\title{
Usability of EFBs for Viewing NOTAMs and AIS/MET Data Link Messages
}

\author{
Emory T. Evans Jr, Steven D. Young, Taumi S. Daniels \\ NASA Langley Research Center, Hampton, VA \\ Robert R. Myer \\ SGT, Inc., Hampton, VA
}

Abstract

Electronic Flight Bags (EFB) are increasingly integral to flight deck information management. A piloted simulation study was conducted at NASA Langley Research Center, one aspect of which was to evaluate the usability and acceptability of EFBs for viewing and managing Notices to Airmen (NOTAMs) and data linked aeronautical information services (AIS) and meteorological information (MET) .

The study simulated approaches and landings at Memphis International Airport (KMEM) using various flight scenarios and weather conditions. Ten two-pilot commercial airline crews participated, utilizing the Cockpit Motion Facility's Research Flight Deck (CMF/RFD) simulator. Each crew completed approximately two dozen flights over a two day period.

Two EFBs were installed, one for each pilot. Study data were collected in the form of questionnaire/interview responses, audio/video recordings, oculometer recordings, and aircraft/system state data.

Preliminary usability results are reported primarily based on pilot interviews and responses to questions focused on ease of learning, ease of use, usefulness, satisfaction, and acceptability. Analysis of the data from the other objective measures (e.g., oculometer) is ongoing and will be reported in a future publication.

This paper covers how the EFB functionality was set up for the study; the NOTAM, AIS/MET data link, and weather messages that were presented; questionnaire results; selected pilot observations; and conclusions.
Acronyms

$\begin{array}{ll}\text { ACARS } & \text { Aircraft Communications } \\ & \text { Addressing and Reporting } \\ \text { AGL } & \text { System } \\ \text { AIRMET } & \text { Above Ground Level } \\ & \text { Airmen's Meteorological } \\ \text { AIS } & \text { Information } \\ & \text { Aeronautical Information } \\ \text { AOC } & \text { Services } \\ \text { ATC } & \text { Airline Operations Center } \\ \text { CMF/RFD } & \text { Air Traffic Control } \\ & \text { Cockpit Motion Facility's } \\ \text { COTS } & \text { Research Flight Deck } \\ \text { DA } & \text { Commercial Off the Shelf } \\ \text { Data Comm } & \text { Decision Altitude } \\ \text { D-ATIS } & \text { Data Communications } \\ & \text { Digital Automatic Terminal } \\ \text { EFB } & \text { Information Service } \\ \text { FAA } & \text { Electronic Flight Bag } \\ \text { HAT } & \text { Federal Aviation Administration } \\ \text { IAP } & \text { Height Above Touchdown } \\ \text { ILS } & \text { Initial Approach Procedure } \\ \text { KMEM } & \text { Instrument Landing System } \\ \text { LOC } & \text { Memphis International Airport } \\ \text { MET } & \text { Localizer } \\ \text { METAR } & \text { Meteorological } \\ & \text { Aviation Routine Weather } \\ \text { MSL } & \text { Report } \\ \text { NEXRAD } & \text { Mean Sea Level } \\ \text { NM } & \text { Next-Generation Radar } \\ \text { NOTAM } & \text { Nautical Mile } \\ \text { PIREP } & \text { Notice to Airmen } \\ \text { PFD } & \text { Pilot report } \\ \text { RNAV } & \text { Primary Flight Display } \\ \text { SID } & \text { Area Navigation } \\ \text { SIGMET } & \text { Standard Instrument Departure } \\ \text { TAF } & \text { Significant Meteorological } \\ & \text { Information } \\ \text { Terminal Aerodrome Forecast }\end{array}$




\section{Background}

EFBs are used in current airline operations, but on a relatively small scale, and with somewhat limited functionality with respect to their potential. EFBs can display a variety of aviation data. Some of this information has been traditionally provided in paper form or based on data provided to the crew by an airline's flight dispatch function. Operators and flight crews are transitioning from paper products in a traditional flight bag to an electronic format.

EFBs may be portable (Class 1), attached to a mounting device (Class 2), or built into the aircraft (Class 3) [1].

An industry survey of Class 1,2 , and 3 EFB capabilities was conducted in 2010 [2]. The survey was conducted among:

- 18 systems manufacturers who provide both EFB hardware and software

- 5 software manufacturers who offer integrated and customizable software without hardware

- 53 software manufacturers who provide commercial off-the-shelf (COTS) software not integrated or tailored for a particular EFB.

Table 1 shows the range of EFB capabilities and applications that the survey found were supported. The capabilities are listed in aggregate descending order of prevalence.

The survey does not explicitly break out the capability to access NOTAMs or AIS/MET information, however much of this type of information is embedded in categories Flight Planning and Weather.

The FAA provides guidance on the operational use of EFBs through [1]. It provides some key EFB design recommendations:

- EFBs may display data linked AIS and MET information for advisory use to support strategic decision making and to enhance situational awareness.
Table 1. EFB Capabilities

\begin{tabular}{|l|c|c|c|}
\hline Capability & $\begin{array}{l}\text { System } \\
\text { Mfrs, } \\
\text { \% }\end{array}$ & $\begin{array}{l}\text { Int'ed } \\
\text { SW, } \\
\text { \% }\end{array}$ & $\begin{array}{l}\text { COTS } \\
\text { SW, } \\
\text { \% }\end{array}$ \\
\hline Electronic charts & 100 & 100 & 4 \\
\hline Flight planning & 78 & 100 & 35 \\
\hline $\begin{array}{l}\text { Flight performance } \\
\text { calculations }\end{array}$ & 100 & 100 & 25 \\
\hline Electronic docs & 94 & 100 & 25 \\
\hline Weather & 39 & 100 & 42 \\
\hline $\begin{array}{l}\text { En route moving } \\
\text { map }\end{array}$ & 83 & 60 & 23 \\
\hline Logbook & 67 & 60 & 19 \\
\hline $\begin{array}{l}\text { Electronic } \\
\text { checklists }\end{array}$ & 89 & 80 & 6 \\
\hline $\begin{array}{l}\text { Surface moving } \\
\text { map }\end{array}$ & 89 & 60 & 6 \\
\hline Video surveillance & 78 & 80 & 2 \\
\hline Terrain display & 56 & 0 & 19 \\
\hline GPS/Nav display & 61 & 0 & 4 \\
\hline Data link & 50 & 40 & 4 \\
\hline Voice data comm & 44 & 20 & 0 \\
\hline Enhanced vision & 44 & 0 & 2 \\
\hline Traffic surveillance & 33 & 0 & 6 \\
\hline Synthetic vision & 22 & 0 & 4 \\
\hline
\end{tabular}

- Data linked graphical weather (e.g. NEXRAD) may be used for strategic/flight planning purposes.

- The EFB user interface should be consistent and intuitive across the EFB and its various applications.

- Electronic aeronautical charts should provide a level of information comparable to paper charts.

- Requirements for approval of airport moving map displays (AMMD) for EFB's are specified in [3]. AMMD's help flight crews orient themselves on the airport surface and improve positional awareness during taxi operations.

- The EFB design should minimize crew workload and head-down time to avoid multi-step tasks during takeoff, landing, and other critical phases of flight. 


\section{Study Set Up}

The assessment reported here was part of a concurrent effort to study how pilot decisionmaking in the presence of complexity is influenced by information management, content, and quality. The results of that larger effort are reported elsewhere [4]. The EFB aspect of the study sought to assess the usability and acceptability of EFBs for providing crews with NOTAMs and data linked AIS/MET information. Some information was presented as text only, some graphical only, and some in both text and graphical forms.

The experiment was hosted by the CMF/RFD over the period from March 27 to May 3, 2013. The physical structure is shown in Figure 1. For this study, the EFBs were repositioned more inboard and lower than shown. Also, the right-side head-up display is not shown. The CMF/RFD simulator has commonalities with the Boeing 757 and 767 (aerodynamic model, handling qualities, flight management system, control display unit, automation mode control panel, center aisle stand and throttle quadrant, and overhead panel), the Boeing 787 (four 17-inch liquid crystal displays, dual HUDs, and dual EFBs), and Airbus aircraft (dual side-sticks).

Over the course of the experiment, 10 twopilot airline crews participated. Each crew consisted of a Captain and First Officer from the same airline, with four airlines represented.
Each crew completed a set of flights into Memphis International Airport (KMEM). All flights began at 10,000 ft MSL, on one of four RNAV-based arrival and approach paths, and at an airspeed of 250 knots. Flights ended nominally after landing and runway exit; however, in many cases the crew decided to goaround. Flight times ranged from 8 to 15 minutes.

Three unique weather conditions were used during the flights. For the first, visibility was 3 $\mathrm{NM}$ and the cloud ceiling was $1000 \mathrm{ft}$. Winds were light, and there was no turbulence or rain. For the second and third conditions, storm models were used based on two events that occurred in 2011, and for which KMEM had significant weather-induced delays. The two storms were different in intensity and variability. These three models drove the motion-platform (e.g. winds and turbulence effects) and for this part of the study, determined what weather information should be provided on the EFBs. For more on how the weather environment was created and used to drive the flight simulation see [5].

Data communications (Data Comm) was implemented as follows. Messages from ATC were displayed on the PFD and the EFBs. The EFBs were used for reviewing and accepting or rejecting the ATC messages. Each incoming message was announced via a chime. NOTAMs and weather information were provided as a preflight load on the EFB (e.g. to support pre-flight briefings) and via data link in flight.
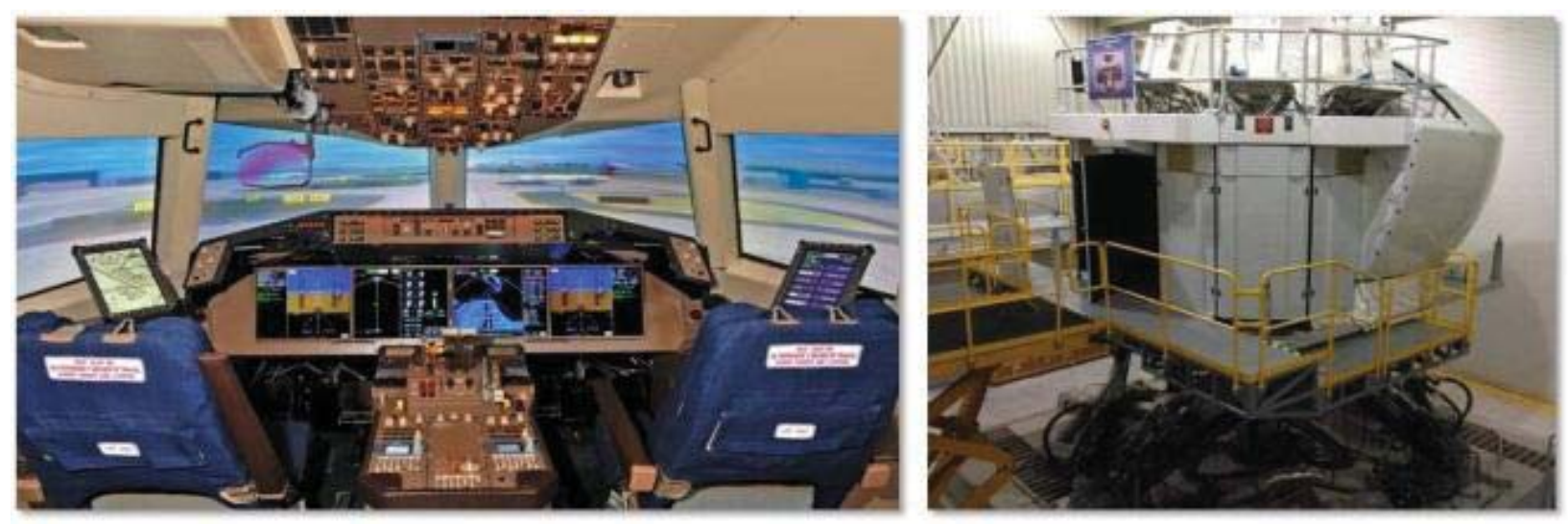

Figure 1. Cockpit Motion Facility's Research Flight Deck 
Data from the study were collected in several forms including interview and questionnaire responses, audio/video recordings, pilot input (e.g. button presses), head and eye tracking, and pilot and researcher observations. Short questionnaires were completed by each pilot following each flight.

\section{EFB Functionality for Study}

It was the intent of this study to adhere to EFB-related current standards and practices and to mimic and extend current products and capabilities.

A baseline set of EFB functions was implemented consistent with current state-ofthe-practice. From the main menu of the EFB, seven categories of information were available:

- Communications

- Weather

- NOTAMs

- Charts

- Airport Moving Map

- Checklists

- D-ATIS

Two Class 3 EFBs were installed, left and right, to allow each pilot to access information independently. (FAA regulations require at least two operational EFBs in order to remove paper aeronautical charts, checklists, or required data from the flight deck. [1]) Data link messages were echoed on both units. This enabled functions such as acknowledging messages to only have to be done from one EFB.

On receipt of a data link message, either from ATC or via the AIS/MET service, one of the pilots was required to review the message, discuss it with the other pilot, then reply using the EFB (e.g. via a "wilco" message). Prior to the start of each flight, the crew was required to review and discuss current NOTAMs and weather information stored in the EFB. The crew was required to use the charts and checklists in the EFB per their typical airline procedures.

No paper reference material was available during the experiment, other than a few pages from the operating manual and quick reference handbook that were occasionally needed to support emergency checklist items.

For this experiment, the AIS/MET data link functionality was consistent with the current aviation industry concept of use for AIS/MET data link services [6]. Depending on the scenario flown, the AIS/MET messages received during a flight were drawn from the following:

- Temporary obstruction (text and graphic)

- Operationally significant NOTAMs (text and graphic)

- Changes to instrument approach procedures (text and graphic)

- Runway braking action reports (text only, no graphic)

- Runway winds (text only, no graphic)

- Pilot reports (text only, no graphic)

The airport moving map functions and displays were implemented as in [7], with some changes and additional features. The moving map depicted locations of runway and taxiway edges, painted markings, and buildings, with overlays of aircraft position, traffic positions, and the ATC-provided taxi route. The taxi route was provided via Data Comm. The moving map was integrated with the NOTAM system such that geo-referenced NOTAMs were displayed graphically (e.g. closed runways).

The EFB layout is shown in Figure 2 (inactive buttons are grayed-out). The main menu page was visible at startup and accessible at any time by pressing the MENU button at the top of the tablet.

The usable screen size was 6.2 " wide by 8.3" high and the resolution was $1024 \times 768$ (XGA). 


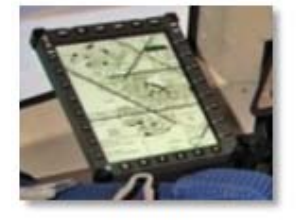

Left EFB

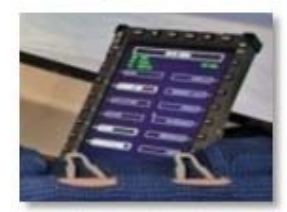

Right EFB

Pilots access sub-menus by pressing touchscreen label or the associated bezel button

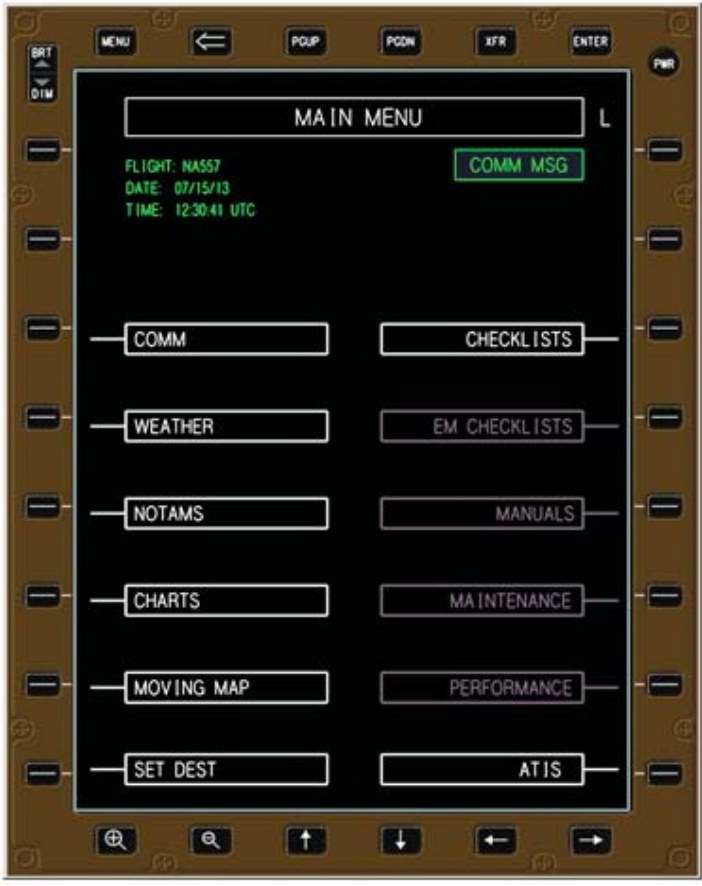

- COMM - To review and acknowledge data link messages from ATC and the AIS/MET service

- WEATHER - To review MET reports (METARs), Terminal Area Forecasts (TAFs), Airmen's MET reports (AIRMETs), Pilot reports (PIREPs), Winds aloft, and composite ground-based radar images

- NOTAMs - To review NOTAMs in text and graphic forms (during pre-flight or when received in-flight via the AIS/MET service)

- AIRPORT MOVING MAP - To view airport features with position overlay, traffic, and taxi route

- CHARTS (Arrival, Approach, Airport)

- CHECKLISTS (Descent, Landing, Taxi)

- ATIS (Automatic Terminal Info Service)

Figure 2. EFB Functionality

\section{Comm Pages}

Upon receipt of a data link message, "COMM MSG" is displayed in green in the upper right portion of the EFB. A chime is also provided. The "COMM MSG" indication remained until all data link messages were responded to. On the COMM page the text of data link messages is green until a response is sent, at which time, the text turns white. See Figure 3.

AIS/MET messages are displayed in order of receipt, with most recent at the top. A "(G)" in front of the message indicates an associated graphic is available. Touching the $(\mathrm{G})$ message or pressing the associated bezel button brings up the message in graphical form. Acknowledging a message changes the text to white. Unacknowledged messages remain green.

The most recent ATC data link message is displayed in the upper portion of the page.

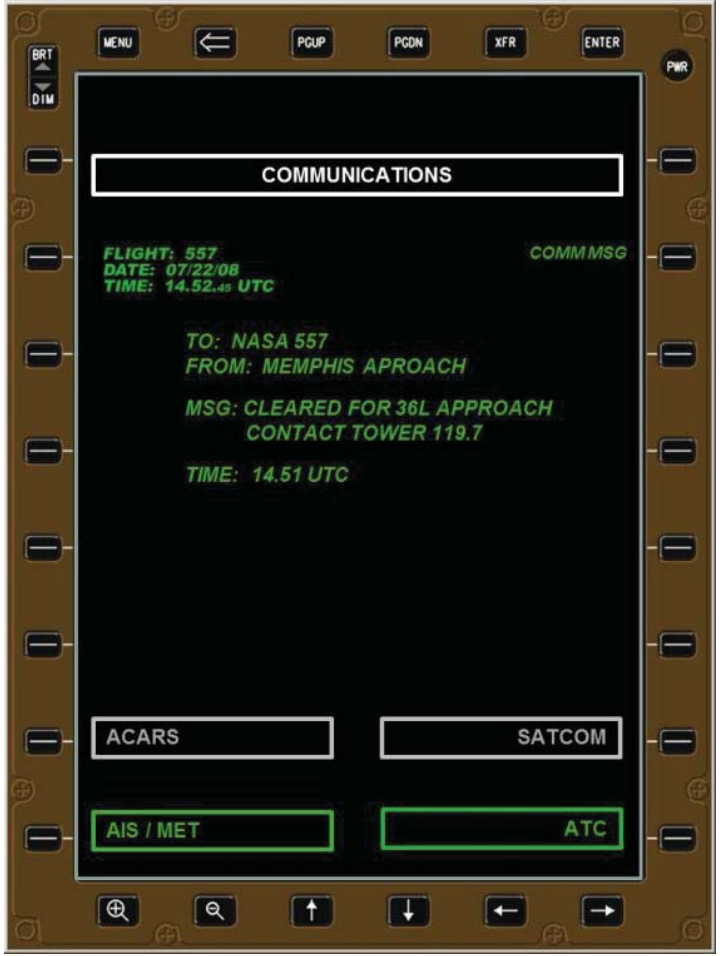

Figure 3. Communications Page 


\section{Weather Pages}

The following weather products were available on the EFB for this study:

- METAR (text)

- TAF (text)

- D-ATIS (text)

- Winds (graphic)

- NEXRAD (graphic)

- $\quad$ AIRMET Sierra (text plus graphic)

- AIRMET Tango (text plus graphic)

- AIRMET Zulu (text plus graphic)

- PIREPs (text plus graphic)

All were provided in a form similar to that from current commercial EFB solution providers (e.g., ForeFlight, Garmin Pilot, WingX). The information content for these depended on which of the three weather models was used in a given scenario. For a detailed explanation of these weather products see [8]. For more information on how Winds and NEXRAD graphics were created based on the weather models see [5].

\section{NOTAMs Pages}

As with the AIS/MET messages, a "(G)" in front of the text indicates that an associated graphic is available. Each text NOTAM is associated with a button on the left side of the EFB. Pressing it displays the corresponding graphical NOTAM. See Figure 4 for an example NOTAMs page.

\section{Airport Moving Map Page}

The airport moving map page is described in [4] and [7].

\section{Charts Pages}

The CHARTS pages provide the published arrivals, approaches, departures, and airport diagram for KMEM.

\section{AIS/MET Messages}

AIS information is defined in [9]. The AIS messages used in this study were developed in accordance with [6], which represents the

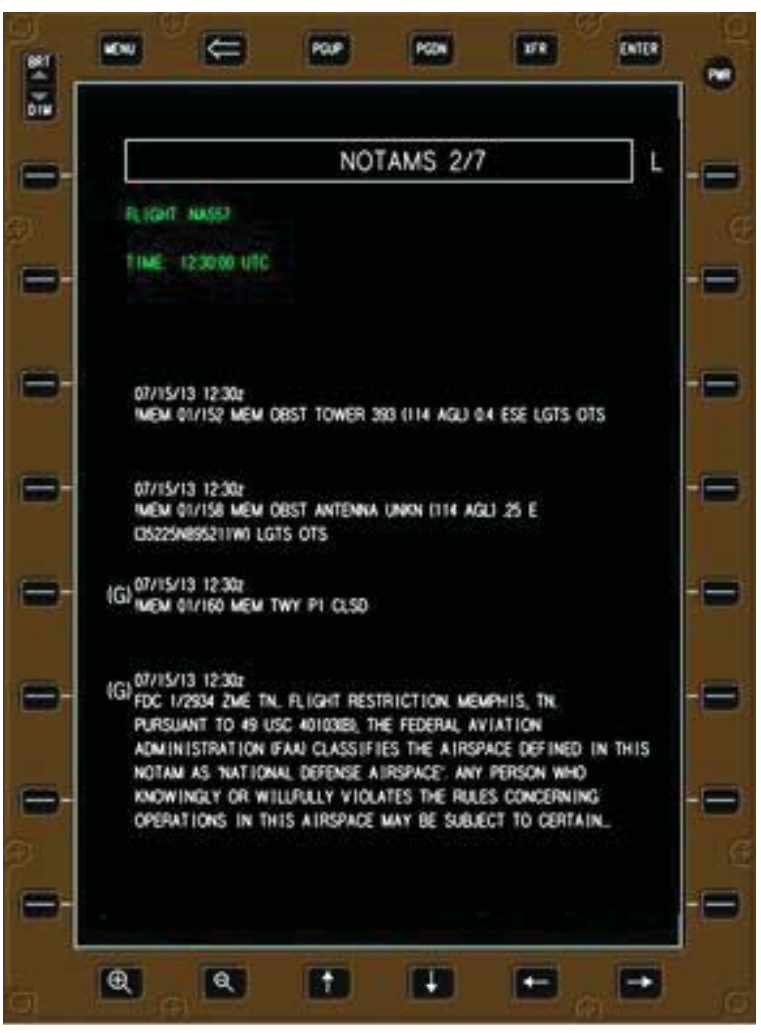

Figure 4. NOTAMs Page

aviation industry view on how AIS and MET data link services would support flight operations in the future. The following AIS messages (text and graphic forms) were used in the study:

"KMEM Rwy 18R/36L north $500 \mathrm{ft}$ closed"

"Change to IAP for ILS or LOC Rwy 36C. DA $551 \mathrm{ft}$. HAT $230 \mathrm{ft}$. RVR $2400 \mathrm{ft}$ ”

“MEM Temporary Obstruction. Crane 0.15 NM west of approach to 36L. Height 401 MSL (60 AGL) at 350214N, 892921W"

The following MET messages (text only) were used:

"KMEM PIREP: Low level wind shear, +/- 10 knots, surface to $1000 \mathrm{ft}$ during approach, Runway $18 C^{\prime \prime}$

"Runway $18 \mathrm{C}$ braking condition poor"

"Runway 36C arrival, current threshold wind from 180 degrees at 10 knots"

Figure 5 shows the graphic that was used for "KMEM Rwy 18R/36L north 500 ft closed." 


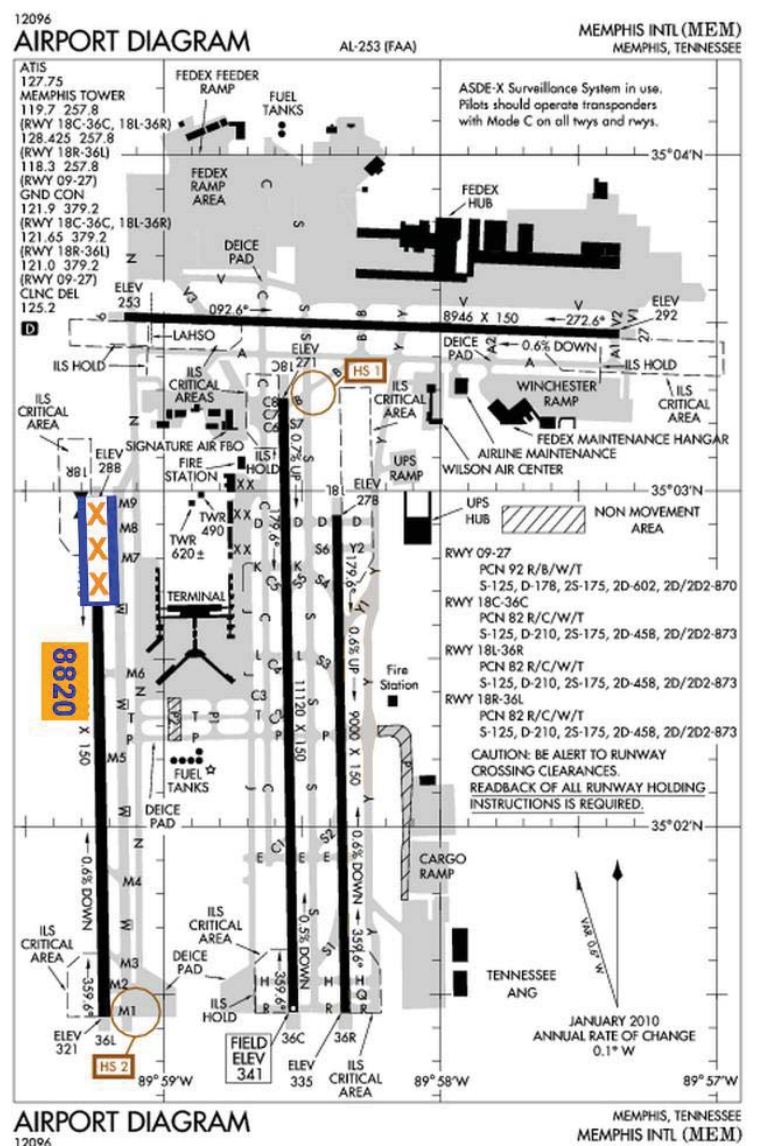

Figure 5. Runway 18R/36L N 500 ft Closed

\section{NOTAMs}

About two dozen NOTAMs were loaded into the EFB for each scenario. The quantity and type NOTAMs used in the study were consistent with historical KMEM NOTAMs. Those used in the study were developed from published NOTAMs for KMEM available from the US NOTAM system at [10].

These were tracked over time to develop a representative sample. The NOTAMs were not filtered or tailored to the specific flight and thus many were not pertinent. This was done for consistency with the current NOTAM environment. Traditional text format NOTAMs used in the study included:

- Change to departure procedures

- Change to arrival procedures

- Airport equipment out of service

- Lights out of service
- Birds in vicinity of airport

Some graphical NOTAMs were based on the work of SAE G-10A, which at the time of this study was developing [11]. These graphical NOTAMs were:

- Runway closed

- Runway shortened

- Taxiway closed

- Glide path out of service

- Change to instrument approach procedure

Other graphical NOTAMs used were:

- Special Use Airspace

- Airborne laser operations

- Temporary Flight Restriction

All graphical NOTAMs had associated text in the traditional NOTAM format available via the SHOW/HIDE TEXT button. See Figure 6 for an example.

\section{Results}

Preliminary findings are presented here regarding usability and acceptability of the EFBs for reviewing NOTAMs and AIS/MET data link messages. Selected pilot comments are also provided. Data analysis continues and a more comprehensive set of results will be presented in a future publication. This will include, for example, an analysis of oculometer data to determine the amount attentional resources used by the pilots to interact with EFBs during the approaches.

For the 10 commercial crews ( $\mathrm{n}=20$ pilots) that participated, response percentages when asked for their current method of accessing NOTAMs during preflight were:

- Paper (81.8\%)

- Paper and EFB (9.1\%)

- Paper, EFB/tablet, ACARS (4.5\%)

- EFB/tablet (4.5\%) 


\section{IMEM 03/032 MEM RWY 18C/36C CLSD UFN}

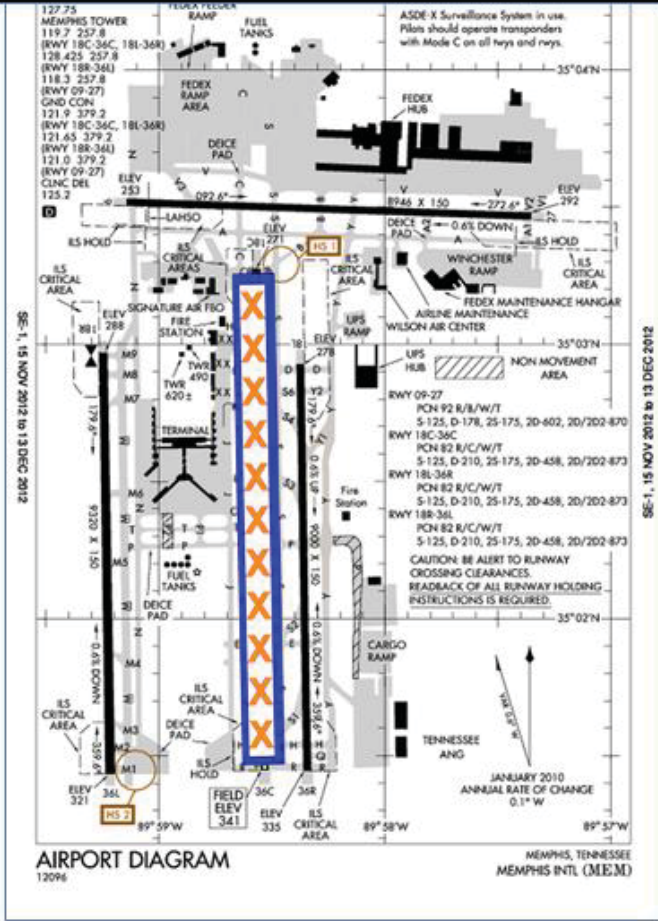

Figure 6. Runway 9/27 Closed Until Further Notice (Graphic with Text Overlay)

Response percentages as to the current method of accessing NOTAMs during a flight were:

- ACARS (40.9\%)

- $\quad$ Paper and ACARS (40.9\%)

- $\quad$ Paper (13.6\%)

- Paper and tablet (4.5\%)

The use of EFBs by the crews to access NOTAMs was not a prevalent practice.

\section{Usability}

Usability questionnaires were developed based on [12] and administered individually to each pilot following each flight. Responses were provided using a Likert scale of 1 (Strongly Disagree) to 7 (Strongly Agree). Assessments were limited to the usability of EFBs for viewing and managing NOTAMs and data linked AIS/MET messages. Four categories of usability were assessed:

- Usefulness
- Ease of use

- Ease of learning

- Satisfaction

Pilots rated multiple subfactors for each of these categories. Results are summarized and presented in Figures 7 through 10. Pilots rated usability with respect to pre-flight use and inflight use. The percentage of responses for a given rating is shown to the right of the bars in the figures. For each category, three statistical measures are shown: median $(\bar{x})$, mode $(\mathrm{Mo})$, and number of responses (n). The number of responses varies, mainly because the number of subfactors for each of the four categories was not equal, but also because subfactor ratings were occasionally left blank.

As indicated by Figure 7, Usefulness was rated high by a large preponderance of the pilots for both preflight and in-flight. The median Usefulness rating was 6 or 7 in $80 \%$ of the preflight responses $(46 \%+34 \%)$ and in $79 \%$ of the in-flight ratings $(41 \%+38 \%)$. Also, there is no significant difference between preflight and inflight use. For both preflight and in-flight the median response was 6 and the mode was 7 and over $90 \%$ of the responses were 5 or above.

The results for Ease of Use (Figure 8) are more mixed. For preflight the median response was 6 and the mode was 7. For in-flight the median response was 6 but the mode fell to 5 . This is due in part to the fact that reaching certain pages on the EFB required multiple button presses.

Ease of Learning was very highly rated, both for preflight and in-flight use (Figure 9). Most pilots had little difficulty learning to use the EFB and quickly becoming proficient.

Although still high, Satisfaction was the lowest rated usability component (Figure 10). This reflects some of the dislikes listed in the Pilot Comments section below and is related to aspects of page navigation, distracting messages, the message acknowledgement process, and the lack of message filtering or tailoring to the specific flight (although that is consistent with today's NOTAM environment). All of these issues can be resolved during the design refinement process. 


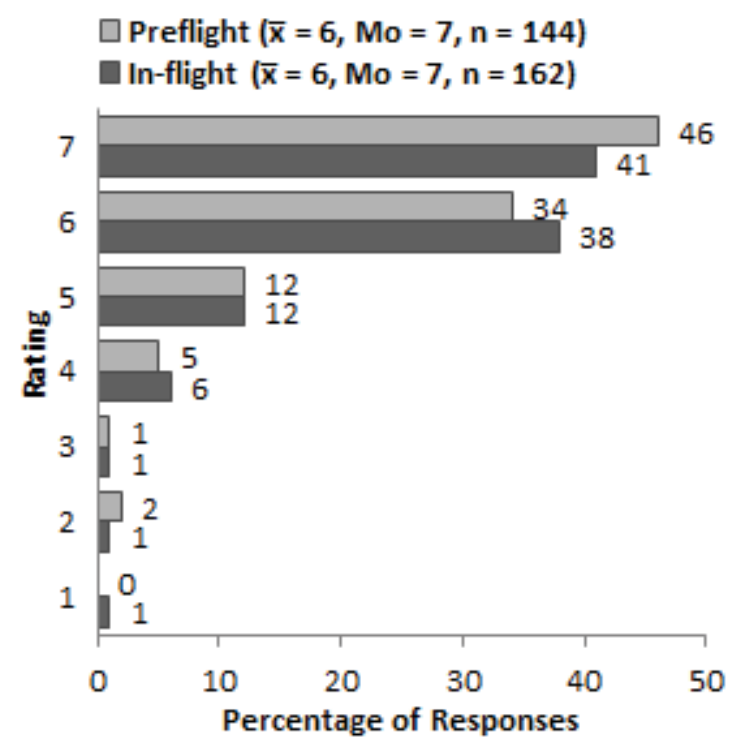

Figure 7. Usefulness Ratings

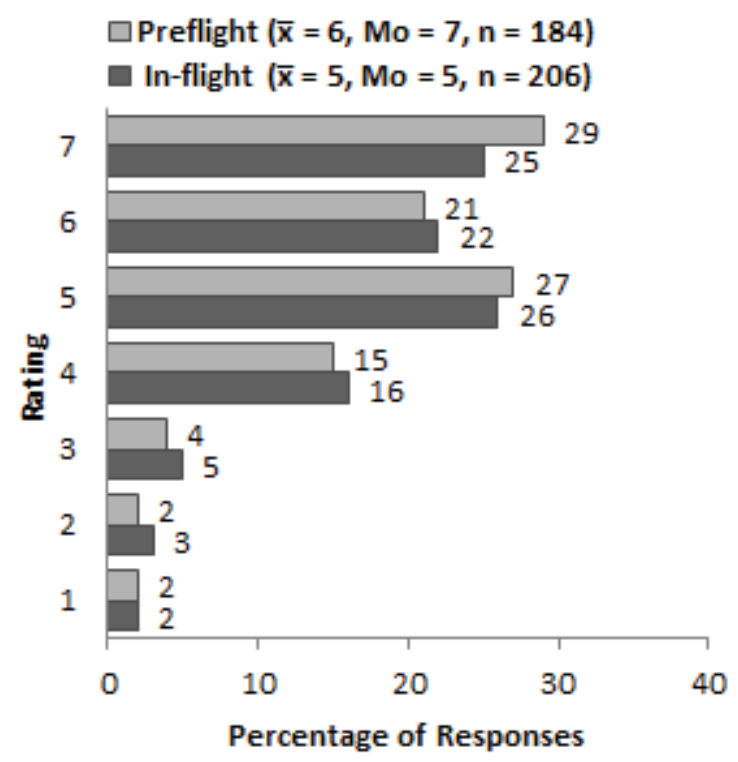

Figure 8. Ease of Use Ratings

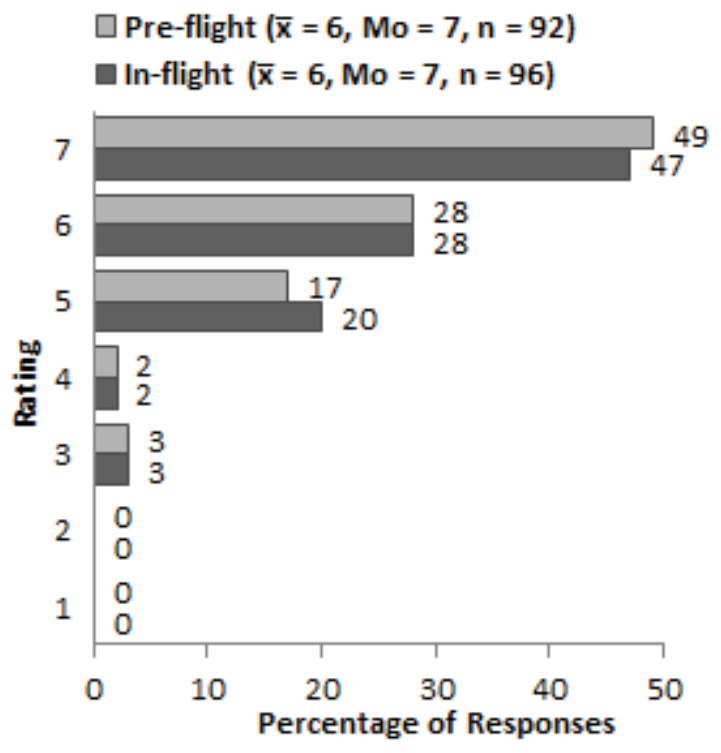

Figure 9. Ease of Learning Ratings

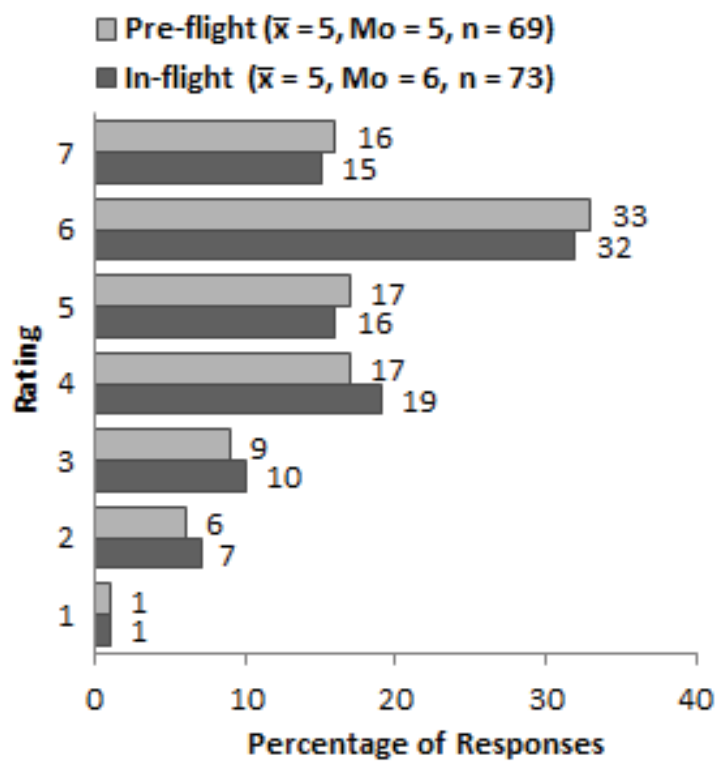

Figure 10. Satisfaction Ratings 


\section{Acceptability}

Acceptability was assessed through pilot ratings of the eight factors listed in Table 11 . Pilots rated the factors on a Likert scale of 1 (Completely Disagree) to 7 (Completely Agree). Summary results are given in Table 11 for Part 1 and Part 2 separately. In Part 1 use of the EFB was introduced to the pilots and there were fewer complexities involved in the operations (e.g. no traffic). In Part 2, complexity was increased by introducing off-nominal events, adding traffic, and requiring the pilots to maintain prescribed spacing with lead aircraft [4]. The number of responses (n) is greater for Part 2 than for Part 1 because more scenarios were flown in Part 2.

Table 11. Acceptability Factors and Ratings

\begin{tabular}{|c|c|c|c|c|c|c|c|}
\hline \multirow[b]{2}{*}{$\#$} & \multirow[b]{2}{*}{ Factor } & \multicolumn{2}{|c|}{ Median } & \multicolumn{2}{|c|}{ Mode } & \multicolumn{2}{|c|}{$\mathrm{n}$} \\
\hline & & $\begin{array}{c}\text { Part } \\
1\end{array}$ & $\begin{array}{c}\text { Part } \\
2\end{array}$ & $\begin{array}{c}\text { Part } \\
1\end{array}$ & $\begin{array}{c}\text { Part } \\
2\end{array}$ & $\begin{array}{c}\text { Part } \\
1\end{array}$ & $\begin{array}{c}\text { Part } \\
2\end{array}$ \\
\hline 1 & $\begin{array}{l}\text { I was aware of the AIS/MET data link messages within } \\
\text { an appropriate timeframe }\end{array}$ & 6 & 6 & 6 & 6 & 67 & 219 \\
\hline 2 & $\begin{array}{l}\text { I was surprised to notice that an AIS/MET data link } \\
\text { message was sent and wondered how long ago it has } \\
\text { been sent }\end{array}$ & 2 & 1 & 2 & 2 & 67 & 222 \\
\hline 3 & $\begin{array}{l}\text { I was aware of all relevant NOTAMs throughout the } \\
\text { scenario }\end{array}$ & 6 & 6 & 6 & 6 & 67 & 226 \\
\hline 4 & $\begin{array}{l}\text { Use of the EFB for awareness of the NOTAMs and } \\
\text { AIS/MET information in this scenario is acceptable }\end{array}$ & 6 & 6 & 6 & 6 & 67 & 225 \\
\hline 5 & $\begin{array}{l}\text { The NOTAM and AIS/MET information I received are } \\
\text { operationally realistic }\end{array}$ & 6 & 6 & 6 & 6 & 66 & 225 \\
\hline 6 & $\begin{array}{l}\text { Time required for EFB tasks did not detract from } \\
\text { having appropriate situation awareness for other } \\
\text { aspects of flight }\end{array}$ & 5 & 6 & 6 & 6 & 67 & 219 \\
\hline 7 & $\begin{array}{l}\text { I received AIS/MET data link messages when in the } \\
\text { process of completing other critical tasks }\end{array}$ & 5 & 6 & 6 & 6 & 65 & 223 \\
\hline 8 & $\begin{array}{l}\text { At no point in this scenario did I feel the NOTAM or } \\
\text { AIS/MET information conflicted with other available } \\
\text { information }\end{array}$ & 6 & 6 & 6 & 6 & 66 & 219 \\
\hline
\end{tabular}

These ratings indicate that the EFBs were generally acceptable to pilots for reviewing and managing NOTAMs and AIS/MET data link messages. Some improvement in median rating is seen going from Part 1 to Part 2, despite the added operational complexity. Median ratings improved for factors 2 and 6. Although the complexity of the scenarios significantly increased in Part 2, the pilots were less often surprised to notice an AIS/MET message and felt more strongly that the time required for EFB tasks did not detract from situational awareness for other aspects of the flight. These improved ratings can be largely attributed to the benefit of familiarization with the EFBs during Part 1 and a resultant increase in proficiency with using the EFB during Part 2. Only factor 7 was rated less acceptable in Part 2. This is not surprising since by design the pilots were occupied with more critical 
tasks in Part 2. The mode for each factor indicates good acceptability and remained unchanged from Part 1 to Part 2.

\section{Pilot Comments}

The following list provides selected comments and suggestions from the pilots. As with any such study, pilots sometimes present inconsistent viewpoints; however, below the salient issues are presented.

\section{Likes:}

1. The EFB as a message listing and viewing concept was well received. It minimized looking at different places for information.

2. A graphic display is worth 1000 words. Graphical NOTAMs and AIS/MET messages offer very quick understanding versus reading text and are easy to follow. They cut through reams of text, and save time for crews by highlighting important information.

3. Using the charts to display the ILS glide path out of service NOTAM and change to approach procedure NOTAM was very effective: easy to identify, easy to follow, easy to apply.

4. The aural notice of a new AIS/MET message was helpful, especially during high workload when a message might otherwise be missed.

5. AIS/MET messages alert the crew to safety issues that may have been missed during preflight or from new conditions developing. Also, messages relating to airport conditions are valuable as backup to tower controllers. Redundancy can be good.

\section{Dislikes:}

1. A big frustration was that several key strokes were sometimes required to get back to the page needed, especially the approach plate and key charts. Pilots want to be able to get back quickly, without using two or three keystrokes.

2. Only NOTAMs and AIS/MET messages that are significant to the flight should be shown. Irrelevant messages should be filtered out. If a message did not affect the flight, most pilots did not want to know about it. For example, "I don't need to know that last $500 \mathrm{ft}$ of runway $36 \mathrm{~L}$ is closed if I'm landing on runway 36C." However, significant weather changes would always be good to know. If something just changed from the last ATIS, it should be data linked up.

3. Distracting messages that come during a critical phase of flight (e.g., at low altitude during approach) are not good. Messages should be minimized to urgent issues like windshear, poor braking action, or weather minima change. Pilots need to know what to expect on approach by top of descent, not inbound at final approach fix or later.

4. The acknowledge process needs to be quicker and not require losing the displayed chart. Some messages should maybe require no acknowledgement or just a click to Accept, Reject, or Cancel. Having to cycle to a different page and back is cumbersome and wastes valuable time in a critical phase of flight. Available responses could be displayed with the comm message when selected. Once the response is made, the display should go back to prior page.

5. When the graphical taxi route is shown crossing a closed runway, there should be a visual indication that it is OK to cross the closed runway. Otherwise it creates confusion as to whether the aircraft is cleared to cross.

\section{Suggestions to improve EFB functionality:}

Note: These suggestions pertain to the EFB as configured for this study.

1. Set up the EFB with the icons on the screen and a "home" button to show the last viewed pages for quick selection.

2. Add pinch and stretch capability for zooming (two-finger touchscreen capability).

3. Make the NOTAM text change color after the graphic is accessed to show that the NOTAM has already been viewed.

4. The depiction of closed runways and taxiways with X's was good, but consider flashing also to increase attention.

5. Tie the FMS and EFB together so that if an arrival and approach is selected on the FMS it 
comes up on the EFB without having to look for it.

6. Add the capability to create pilot-defined buttons to get the needed information with one button press without going back through the menus (i.e. hot-keys).

7. Add a hot key or auto return to the approach plate.

8. Add a hot key for the missed approach chart.

9. Add an alert light or flashing button indicator for new AIS/MET messages.

10. Add automated notification of ATIS updates.

\section{Next Steps}

The next steps for this research are to analyze the data in greater detail by looking at the impact of weather, scenario complexity, and the alternating roles (flying/monitoring) of the two pilots in each flight. In addition there are other data from this study yet to analyze, including the head and eye tracking data (e.g. to determine how much attention is being taken by EFBs and by which pages and when and how they are used) and the audio/video data. There were some cases where pilots may have been using the EFBs more often than necessary, or desired, pulling their attention away from otherwise important tasks. Oculometer data along with EFB page switching recordings can help to quantify this issue.

After the results of this study are assimilated, future follow-on studies are envisioned to address issues that have been identified. Certainly this study points to many opportunities to improve the usability of future EFBs for viewing and managing NOTAMs and AIS/MET data link messages, and to inform evolving standards and regulations related to same.

\section{Concluding Remarks}

In this study commercial airline pilots rated EFBs for usability and acceptability for viewing and managing NOTAMs and AIS/MET data link messages. Most of the pilots had little to no prior experience with this concept. However, in general they learned quickly, becoming proficient in a relatively few number of flights.
In general the pilots rated the usability and acceptability of the EFBs well, but offered suggestions for improving the user experience based on their operational needs. These suggestions are insightful and merit further attention.

After observing pilot interactions with the EFBs over the course of 240 approaches, several common themes emerge:

1. Procedures for utilizing EFBs for reviewing/managing NOTAMs and AIS/MET data link messages must be welldefined; particularly in a two-pilot crew environment.

2. The value of an EFB as a message listing and viewing tool was evident. Using EFBs to display and manage NOTAMs and AIS/MET information can enhance situational awareness and have clear operational benefit.

3. Pilots tended to learn to use the EFB quickly adapted readily to a paperless cockpit environment. However, there were cases where paper may have benefited (e.g. when navigating away from a chart page).

4. Extensive navigation among the several pages and functions increases workload to an undesirable and potentially unacceptable level. This may lead to an alternate form of automation mode confusion (i.e., EFB mode confusion); there was one case where the two pilots were viewing different charts, each believing they were looking at the correct one.

5. The power of graphical presentations to convey understanding and awareness quickly was clear. Pilots always preferred graphical NOTAMs and AIS/MET messages to text form. Information should be presented graphically wherever possible.

6. Information retrieval should be quick and straightforward. Access to relevant charts in a timely manner is essential. An intelligent or "smart" EFB may be the best solution for some situations (e.g., pop-up info that is new and has critical operational importance). 
7. During periods of high workload, especially on final approach, distracting messages on the EFB should be minimized. Voice was the preferred means to pass information inside the final approach fix or below a given altitude (e.g., $1500 \mathrm{ft}$ AGL). Only urgent AIS/MET messages should be sent beyond this point.

8. Pilot interaction with the EFB in critical phases of flight should take the fewest button pushes possible, preferably one.

9. NOTAMs and AIS/MET messages should be filtered and tailored to the flight. Ideally, only relevant information should be sent/displayed.

10. All taxiway and runway closures should be available for view on a single diagram. For example, issue a single NOTAM ("Airport closures, see chart").

The study reinforces some time-tested usability maxims [13]:

- The information for the decision should be there when the decision is needed.

- Don't overwhelm the user.

- Keep it simple.

- The best journey has the fewest steps. Shorten the distance to the goal.

Ideally, EFB's should be useful, easy to use, easy to learn, and satisfying to use. The results show that in this study they generally were, but there is room for improvement in future implementations.

\section{Acknowledgements}

The authors would like to thank the SAE G-10A Aeronautical Information System Committee for their valuable contributions on graphical NOTAMs, Jim Barnes and NASA Langley's simulation development team, and Dr. Maarten Ujit de Haag and Pengfei "Phil" Duan of Ohio University.

\section{References}

[1] FAA Advisory Circular (AC) 120-76B, Guidelines for the Certification, Airworthiness, and Operational Use of Electronic Flight Bags. June 1, 2012.
[2] Gabree, S., Yeh, M., Young, J. J., Electronic Flight Bag 2010 Industry Survey. September 2010.

[3] FAA Advisory Circular (AC) 20-159, Obtaining Design and Production Approval of Airport Moving Map Display Applications Intended for Electronic Flight Bag Systems. April 30, 2007.

[4] Young, S. D., Daniels, T. S., Evans, E. T., Uijt de Haag, M., and Duan, P., "Understanding Crew Decision-Making in the Presence of Complexity A Flight Simulation Experiment," AIAA InfoTech Aerospace Conference, Boston, MA, Aug $19-22$ 2013.

[5] Daniels, T. S., Schaffner, P. R., Evans, E. T., and Young, S. D., "Motion-Based Piloted Flight Simulation Test Results for a Realistic Weather Environment," Digital Avionics Systems Conference (DASC), 2013 IEEE/AIAA 32nd, 2013.

[6] RTCA DO-340 Concept of Use (ConUse) for Aeronautical Information Services (AIS) and Meteorological (MET) Data Link Services. September 26, 2012.

[7] Prinzel, L. J., et. al., Flight Deck-Based Delegated Separation: Evaluation of an On-board Interval Management System with Synthetic and Enhanced Vision Technology, Proceedings of the $30^{\text {th }}$ AIAA/IEEE Digital Avionics Systems Conference, Seattle, WA, October 2011.

[8] FAA Advisory Circular (AC) 00-45G Aviation Weather Services, Change 1. July 29, 2010.

[9] ICAO Annex 15 Aeronautical Information Services. $13^{\text {th }}$ Edition. November 18, 2010.

[10] https://pilotweb.nas.faa.gov/

[11] SAE G-10A Aerospace Recommended Practice (ARP) 6467 Cockpit Display of Data Linked Aeronautical Information. (Draft)

[12] Lund, A., Measuring Usability with the USE Questionnaire, Usability Interface Newsletter, Vol. 8, No. 2, Usability Special Interest Group, Society for Technical Communication, October 2001.

[13] Lund, A. Expert Ratings of Usability Maxims. Ergonomics in Design, 5(3), 15-20.

32nd Digital Avionics Systems Conference October 6-10, 2013 